\title{
Macrófitas aquáticas de um lago marginal ao rio Embu-mirim, São Paulo, Brasil*
}

\author{
Aquatic macrophytes from a marginal pond at Embu-mirim river, S.Paulo, \\ Brazil
}

\section{Zuleika Beyruth}

\begin{abstract}
BEYRUTH, Z. Macrófitas aquáticas de um lago marginal ao tio Embu-mirim, São Paulo, Brasil. Rev. Saúde públ., S.Paulo, 26: 272-82 1992. Durante os anos de 1984/1985 obtiveramse amostras sazonais para determinação de parâmetros físicos, químicos e biológicos de um lago marginal ao rio Embu-mirim, em Itapecerica da Serra, na bacia do reservatório de Guarapiranga (São Paulo, Brasil). Além de discutir os resultados obtidos quanto à flora de macrófitas aquáticas e suas relações com os outros parâmetros ambientais, são também analisados os efeitos da variação sazonal. As espécies encontradas estão presentes em diversos corpos d'água marginais, bem como ao longo do rio Embu-mirim, permitindo avaliar seu comportamento em corpos d'água semelhantes, da mesma bacia. A macrófita predominante foi Eichhornia crassipes (Mart.) Solms. Os resultados obtidos demostram a tendência de uma eutrofização acelerada e o risco de macrófitas potencialmente problemáticas, como $E$. crassipes e Salvinia auriculata, formarem camalotes de altas densidades, que podem chegar ao reservátorio de Guarapiranga, através do rio Embu-mirim, causando problemas aos diversos usos da água.
\end{abstract}

Descritores: Ervas. Água doce, análise. Eutroficação. Represas.

\section{Introdução}

A grande maioria dos lagos no mundo são pequenos e rasos, com características morfométricas que propiciam o desenvolvimento de extensas comunidades de macrófitas aquáticas em suas regiōes litorâneas, as quais desempenham importante papel no metabolismo de todo o sistema, segundo Wetzel ${ }^{34}, 1975$. Assim, macrófitas e sua microflora e microfauna associadas, podem exercer influência importante na dinâmica trófica dos ecossistemas lacustres.

Gaudet apud Mitchell ${ }^{20}, 1974$, inclui entre as ações e funçōes desempenhadas pelas macrófitas nos complexos aquáticos: a estabilização de sedimentos; a produção primária e a de detritos; a absorção, a acumulação e a liberação de nutrientes (por morte ou excreção); a

* Tese para obtenção de titulo de mestre em Ecologia Geral, apresentada em 1989 no Instituto de Biocièncias da USP, sob o tema: "Avaliaçāo ecológica e sanitária de um lago marginal ao rio Embu-mirim, Itapecerica da Serra e verificaçāo da possibilidade de utilização da macrófita Eichhornia crassipes (Mart.) Solms como indicadora de poluição.

**Departamento de Saúde Ambiental da Faculdade de Saúde Pública da Universidade de São Paulo.

Separatas/Reprints: Z. Beyruth - Av. Dr. Amaldo, 715 01246-904 - São Paulo, SP - Brasil.

Publicação financiada pela FAPESP. Processo Saúde Coletiva 91/4994-0. interferência com o fitoplâncton e com outras macrófitas através do sombreamento e da competição por nutrientes; a diversificação de habitats, servindo inclusive de substrato para o perifiton e de refúgio e nidificação pata animais aquáticos e terrestres, constituindo fonte de alimento a peixes, aves e mamíferos.

Welch $^{33}(1980)$ afirma que as macrófitas aceleram o envelhecimento de um lago provocando aumento na velocidade do processo de assoreamento, por abrigar e consolidar sedimento, já que um lago, do ponto de vista geológico, é um elemento transitório e está gradualmente sendo preenchido.

Pandit $^{26}$ (1984) afirma que as macrófitas de água doce têm uma maior influência sobre a parte física e química do ambiente do que as plantas terrestres.

No lago estudado foram encontradas Eichhornia crassipes (Mart.) Solms, Egeria densa Planch. e Salvinia auriculata Aubl., além de espécimes de Myriophyllum brasiliensis Camb., uma Rubiaceae, uma Onagraceae do gênero Ludwigia e gramíneas.

A literatura sobre Eichhornia crassipes é extremamente extensa, dada a importância ecológica e sanitária assumida por essa espécie durante as últimas décadas.

Esta espécie foi descrita por von Martius a partir de exemplares coletados no Brasil. 
Apresenta ampla distribuição em regiões tropicais e subtropicais. É nativa do Brasil, provavelmente da Região Amazônica, tendo uma distribuição extensiva centrada no Norte e Nordeste do Brasil e Venezuela, sendo particularmente abundante na Região de Pernambuco, Bacia Amazônica e Baixo Orenoco. Pode também estender-se como planta nativa em parte da América Central e nas ilhas maiores do Caribe, ainda que algumas dessas ocorrências possam ser devidas à introdução recente. Durante os últimos 90 anos expandiu sua distribuição nativa. Essa expansão foi espetacular e desastrosa nos ambientes favoráveis ao seu crescimento, tendo-se tornado a mais famosa das ervas daninhas aquáticas, segundo Sculthorpe ${ }^{30}$ (1967).

A despeito de sua importância limnológica e econômica, em regiões tropicais e particularmente no Brasil, o número de trabalhos sobre a ecologia desta espécie em ambientes naturais é relativamente reduzido (Esteves ${ }^{9}$, 1982). Entre eles há os estudos de Rocha ${ }^{29}$ (1975), o de Esteves ${ }^{9}$ e o de Pitelli (1985) apud Palombo ${ }^{25}, 1989$ ) sobre a produtividade destes vegetais em corpos d'água do Estado de São Paulo.

Mitchell $^{21}$ (1976) declara haver relativamente poucos registros de problemas sérios na América do Sul, com a exceção notável da infestação por Eichhornia crassipes no reservatório de Brokopondo no Suriname. Este autor supõe que a escassez de literatura nos ambientes nativos deve-se ao menor número de problemas relacionados a esta espécie em seus ambientes nativos, que em regiões alienígenas. Esta desproporção deve-se à presença de fatores natuais exercendo controle sobre um desenvolvimento explosivo dessa população.

Dentre os possíveis fatores controladores das populaçōes de macrófitas aquáticas nos ambientes originais, Mitchell ${ }^{19,21}$ (1971 e 1976) enumera:

1. Nos neotrópicos, comunidades de macrófitas flutuantes são geralmente formadas por um mosaico de diferentes espécies em competição. Entretanto, E. crassipes pode prover substrato para colonização secundária por outras espécies, favorecendo a presença de um grande número de espécies emergentes, ancoradas, capazes de predominar em corpos d'água rasos.

2. A grande variedade de insetos fitófagos, nativos dessas regiōes e a presença de outros inimigos naturais.

3. $\mathrm{Na}$ América do Sul, em geral, há grandes bacias, com regime hidrológico caracterizado por amplas flutuações no nível da água. Nos períodos de enchente, lagoas e outros corpos d'água marginais, antes isolados, tornam-se parte do rio principal para o qual as macrófitas são arrastadas. Porém, assim que as águas baixem e esses corpos d'água tornem-se novamente isolados, as macrófitas voltam a formar camalotes.

A importância das enchentes dos rios, nesses ambientes nativos, como fator de controle e as possiveis conseqüências da interferência com o sistema natural de fluxo do rio, impedindo este controle, é claramente mostrada pelo aumento explosivo da população de Eichhornia crassipes no reservatótio de Brokopondo. Mitchell ${ }^{19}$ (1971) afirma que a probabilidade de crescimento explosivo dessa vegetação é potencial em todo ambiente tropical, particularmente quando o regime hidrológico é alterado.

A literatura sobre Salvinia auriculata também é escassa, porém o gênero Salvinia, especialmente o chamado complexo Salvinia auriculata, $\left(\right.$ Forno $\left.^{13}, 1983\right)$, mostrou-se extremamente problemático em corpos d'água asiáticos, africanos e australianos. Esta espécie foi descrita por Aublet, a partir de exemplares provenientes da Guiana, tendo ampla distribuição nativa nos neotrópicos, estendendo-se do México e Ilhas Galápagos através da América Central e Antilhas e da maior parte da América do Sul, até o sul do Brasil, segundo Sculthorpe $^{30}$. Quanto à escassez de literatura em sua região de origem e aos problemas causados por este complexo de espécies, pode-se afirmar as mesmas causas e conseqüências relacionadas para $E$. crassipes. Segundo Sculthorpe $^{30}$ estas duas espécies são as macrófitas aquáticas mais agressivas, tendo comprometido diversos usos da água em várias regiōes quentes do mundo, merecendo atenção especial.

Egeria densa, é conhecida como a elódea brasileira e foi descrita por Planchon a partir de espécimes da América dos Sul. Esta espécie tem sido muito utilizada em aquários e investigações científicas.

Sua expansão adventicea tem causado problemas locais devido à sua tendência em tornar-se dominante, produzindo grandes estandes. No lago Biwa, no Japão, atingiu em 5 anos 93.\% do volume total do lago, segundo Cook \& Urmi-Konig ${ }^{8}$, 1984. E uma espécie importante na mobilização de nutrientes do sedimento, absorvendo-os através de seu sistema 
radicular e subseqüentemente liberando-os para a massa d'água, devido à sua rápida taxa de decomposição (Barko \& Smart $\left.{ }^{2}, 1980\right)$.

Deve-se também considerar quanto à presença e abundância de macrófitas livre flutuantes, sua capacidade de prover ambiente favorável à proliferação de organismos de importância sanitária, tais como insetos tabanídeos, culicídeos e outros, bem como o de moluscos vetores de doenças.

Poi de Neiff \& Neiff ${ }^{28}$ (1980) citam entre os organismos da fauna associada a camalotes de Eichhornia crassipes do rio Paraná e lagoas marginais, insetos tabanídeos, quironomídeos, culicídeos e caoborídeos, bem como moluscos do gênero Biomphallaria. A presença desses organismos pode causar desde simples incômodo até a propagação de doenças.

Laird $^{17}$ (1988), cita Lemna e Eichhornia como gêneros de macrófitas aquáticas comuns em habitats de larvas de mosquitos. Forattini ${ }^{11}$ (1962), aponta lagoas com densa população de Eichhornia crassipes como criadouro de culicídeos. Pinotti (1951) apud Horsfall ${ }^{15}$ (1972) relata que no Brasil os locais preferidos por Anopheles darlingi são reservatórios grandes, profundos e sombreados pelo desenvolvimento maciço de Pistia e Eichhornia e que essas plantas servem como meio de transporte para as larvas, durante o periodo das cheias.

Forattini $^{11}$ (1962) afirma que a influência de vegetais aquáticos tem sido objeto de investigações, principalmente no que concerne aos anofelinos, citando a conhecida relação entre Anopheles darlingi e Eichhornia e Pistia, relatando que as larvas deste mosquito, o principal vetor da malária nas regiōes endêmicas do Brasil, freqüentemente ocorrem entre os filamentos radiculares desses vegetais, onde encontram abrigo natural.

Natal e $\operatorname{col}^{23}$ (1991) observam que o acúmulo de Eichhornia crassipes fornece habitat propício à proliferação de Culex quinquefas. ciatus, organismos de elevada antropofilia, nas águas poluídas do reservatório de Edgard de Souza, no rio Tietê. $O$ lago estudado também localiza-se nesta bacia hidrográfica.

Para certas espécies de culicídeos, como as do gênero Mansonia e Coquillettidia, as raízes dessas plantas aquáticas são utilizadas para fixação das larvas e pupas, através das quais estas formas imaturas retiram o oxigênio para respiração (Forattini $\left.{ }^{12}, 1965\right)$. A proliferação de macrófitas aquáticas propicia assim o aumento da densidade populacional desses mosquitos que podem chegar a comprometer a qualidade de vida dos habitantes da região.

Outros aspectos de interesse sanitário, relativos à presença e abundância de macrófitas aquáticas, são: a redução do teor de oxigênio dissolvido na água pelo aumento considerável de matéria orgânica produzida quando as macrófitas atingem altas densidades.

Essa matéria orgânica é consumida por microorganismos decompositores, capazes de consumir grande quantidade de oxigênio dissolvido. $\mathrm{Na}$ decomposição anaeróbica que se instala quando todo o oxigênio foi consumido, há produção de gases como o sulfídrico e metano, causando odor e sabor à água. A redução do oxigênio dissolvido impede a sobrevivência dos organismos aeróbios, causando grandes mortandades de peixes e de outros organismos aquáticos. Altas densidades de macrófitas podem prejudicar e aumentar o custo do tratamento da água para abastecimento, bem como dificultar e até mesmo impedir a navegação e os esportes de contato primário, bem como a pesca.

O objetivo deste trabalho é relatar o estudo das macrófitas aquáticas de água aberta, ou seja, Eichhornia, Salvinia e Egeria.

\section{Material e Método}

O estudo das macrófitas aquáticas foi realizado em lago marginal ao rio Embu-mirim, que com ele se comunica, situado a aproximadamente $5 \mathrm{~km}$ da sua desembocadura na $\mathrm{Re}$ presa de Guarapiranga, no bairro da Lagoa, Município de Itapecirica da Serra, Estado de São Paulo (Fig.).

Este lago caracteriza-se por apresentar densa população de macrófitas aquáticas livreflutuantes, com predominância acentuada de Eichhornia crassipes (Mart.) Solms, macrófita esta encontrada em vários outros lagos marginais e remansos ao longo do rio Embu-mirim.

As coletas foram sazonais, iniciando-se no outono de 1983.

As macrófitas aquáticas foram coletadas somente no ponto I (Fig.), nas proximidades da comunicação do rio Embu-mirim com o lago estudado, onde eram mais abundantes.

Os exames e análises físicos, químicos e biológicos foram realizados, segundo os métodos preconizados no APHA $^{1}$ (1975), no laboratório do Departamento de Saúde Ambiental da Faculdade de Saúde Pública-USP e no laboratório do Departamento de Ecologia Geral do Instituto de Biociências/USP (Beyruth ${ }^{3,4,5}$, 

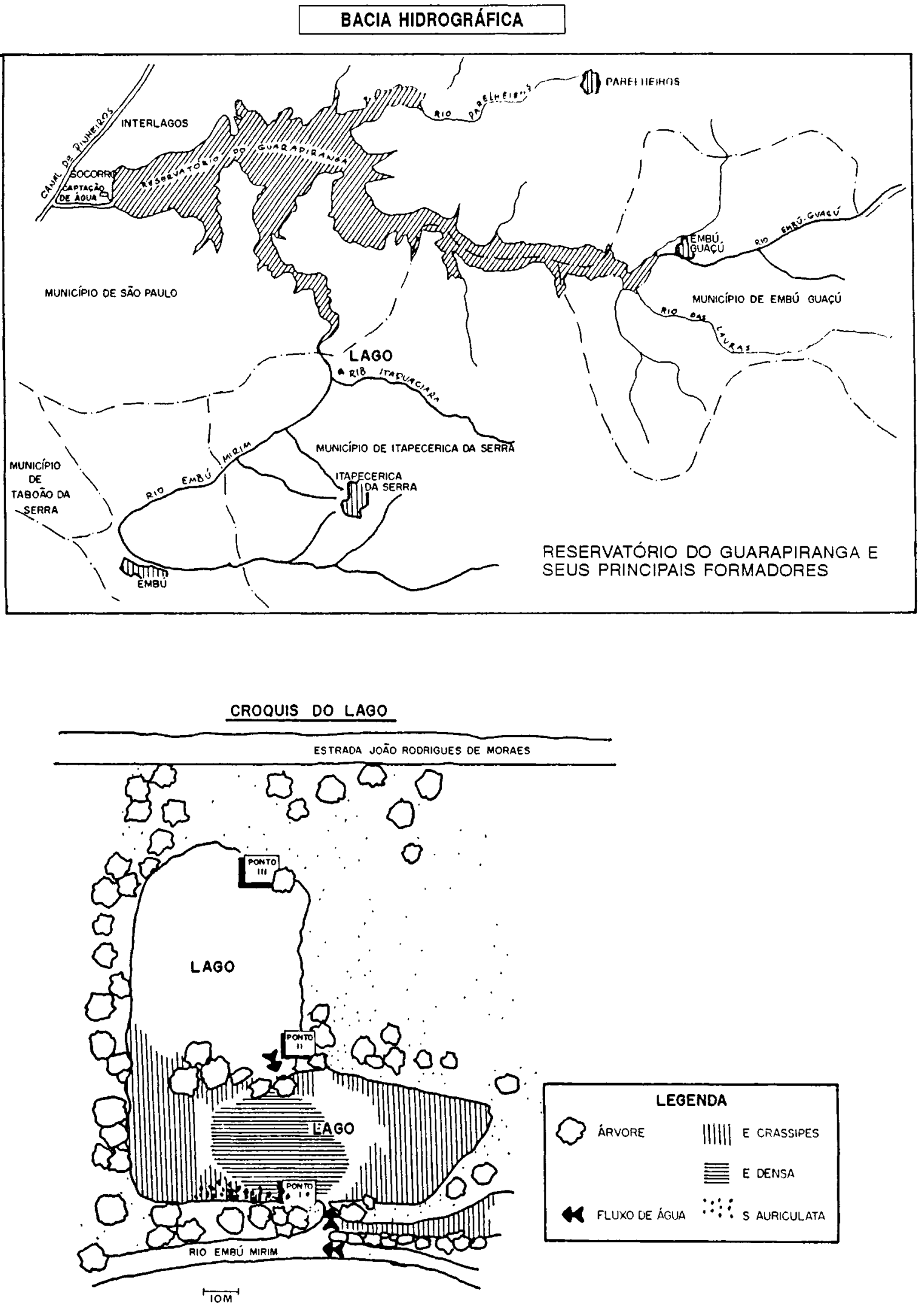

Figura. Mapa da área estudada 
1989, 1990). As análises de nutrientes da água foram realizadas no laboratório da Seção de Radioquímica e Química Analítica do CENA-USP (Centro de Energia Nuclear em Agricultura).

$\mathrm{Na}$ Estação de Hidrometereologia do Departamento de Águas e Esgotos da Cidade Universitária, a mais próxima do lago estudado, foram obtidos além dos dados de horas de sol, as temperaturas mínimas, médias e máximas do ar no período estudado.

As macrófitas foram identificadas na Secção de Herbário do Instituto de Botânica da Secretaria do Meio Ambiente-SP.

Para complementar o estudo, analisou-se fotografias com o registro do que ocorria com a parte aérea das macrófitas emergentes.

Essa avaliação permitiu ilustrar os efeitos causados pela variação do desenvolvimento das plantas, sobre os outros parâmetros bióticos e abióticos analisados.

Para obtenção dos exemplares de macrófitas foram coletadas duas amostras no ponto I, com um quadrado de madeira com vão livre de $0.25 \mathrm{~m}^{2}$. Obtiveram-se amostras dos dois tipos de $E$. crassipes (aguapé) observados no lago: os maiores, posicionados mais ao centro do camalote, e os menores da periferia do camalote. A abundância foi estimada através da observação da proporção de área do lago coberta pelas macrófitas.

Para obtenção de Egeria densa coletou-se somente uma amostra por período, pois o agregado esteve em geral pouco extenso.

No caso de Salvinia auriculata não havia camalote, encontrando-se as mesmas esparsas, associadas ao camalote de Eichhornia, próximas à margem no ponto $I$.

As plantas coletadas foram contadas, acondicionadas em sacos plásticos e levadas para o laboratório, onde após escorrer o excesso de água, verificou-se seu peso fresco. Após secagem em estufa até peso constante, obteve-se o peso seco do conjunto das plantas coletadas. Através dos dados de peso seco e área ocupada, obteve-se a produtividade para as plantas coletadas. Os resultados obtidos foram: número de plantas por área, peso seco médio por planta, área coberta por planta $e$ peso seco por área (produto em pé) total das macrófitas.

Aplicou-se o teste de correlação não paramétrico, de Spearman, indicado por Margalef ${ }^{18}$ (1974), segundo Siegel ${ }^{31}$ (1975), aos partes de variáveis formados pelos dados das macrófitas e os outros dados obtidos no ambiente.

Foram consideradas relevantes as correla- ções (rs) que apresentaram nível de significância entre 95 e $100 \%$ ( $* \star \star>=99,5 \%$; $\star \star>=97,5 \%$; $\star>=95,0 \%$ ), sendo que abaixo desse nivel as correlações foram consideradas não significantes. Utilizou-se o programa SPSS (Nie e col. $\left.{ }^{24}, 1975\right)$, para efetuar os testes de Spearman.

\section{Resultados e Discussão}

As macrófitas encontradas ocorriam na região marginal do lago, principalmente nos arredores da comunicação com o rio. As macrófitas emergentes enraizadas no sedimento atingiram seu maior desenvolvimento na época da seca, no inverno, quando parte da região que ocupavam ficou praticamente emersa. Isso coincidiu com a regressão no desenvolvimento de $E$. crassipes que foi a macrófita mais abundante em todo o período estudado.

As macrófitas estudadas só puderam ser obtidas na região do lago, onde ocorreram em densidade suficiente para permitir sua avaliação. S. auriculata não foi encontrada nas três primeiras coletas.

E. crassipes ao longo das coletas, apresentou menor valor para o produto em peso seco na primavera e o maior no verão (Tabela).

A disposição destas plantas, no lago, nas coletas de outono e de inverno, era semelhante à descrita por Penfound \& Earle ${ }^{27}$ (1948) para colônia bem desenvolvida de aguapé em que as plantas com flutuadores bem evidentes ocorriam somente em água aberta, sendo que as do interior da colônia apresentavam-se desprovidas de flutuadores, mas com folhas mais longas.

E.crassipes atingiram o ápice de seu desenvolvimento vegetativo na primavera, e no verão apresentaram o máximo desenvolvimento reprodutivo, evidenciado pela abundância de plantas floradas. No outono apresentavamse em início de seu período de senescência, que atingiu seu grau máximo no inverno, com as plantas "secando", morrendo e decaindo.

Outono e inverno foram as estaçōes em que elas liberavam consideráveis teores de matéria orgânica e de nutrientes para o ambiente, coincidindo com os maiores teores de nutrientes obtidos na água coletada no inverno. Na primavera e no verão, para suprir seu desenvolvimento vegetativo e reprodutivo, retiravam maiores teores de nutrientes da água.

As análises de nutrientes na água mostram maior teor de nitrato no ponto I, na co- 
Tabela - Macrófitas aquáticas de um lago marginal ao rio Embu-Mirim, SP. Dados de peso fresco, peso seco, densidade, peso seco por área, área coberta do lago.

\begin{tabular}{|c|c|c|c|c|c|c|}
\hline Macrófitas & $\begin{array}{l}\text { Área } \\
\left(\mathrm{m}^{2}\right)\end{array}$ & $\begin{array}{l}\text { Peso } \\
\text { fresco } \\
(g)\end{array}$ & $\begin{array}{l}\text { Peso } \\
\text { seco } \\
(g)\end{array}$ & $\begin{array}{l}\text { Número } \\
\text { de pls. }\end{array}$ & $\begin{array}{c}\text { Peso seco } \\
\text { por área } \\
\left(\mathrm{g} / \mathrm{m}^{2}\right)\end{array}$ & $\begin{array}{c}\text { Área } \\
\text { do } \\
\text { lago }\end{array}$ \\
\hline \multicolumn{7}{|l|}{ Outono 14.05 .84} \\
\hline Eichhornia crassipes & 0,5 & $6.600,0$ & 584,6 & 16 & $1.169,2$ & $40 \%$ \\
\hline Egeria densa & 0,5 & $10.400,0$ & 382,6 & .. & 765,2 & \\
\hline Salvinia auriculata & * & & & & & \\
\hline \multicolumn{7}{|l|}{ Inverno 02.08.84 } \\
\hline Eichhornia crassipes & 0,5 & $3.600,0$ & 704,6 & 14 & $1.409,2$ & $30 \%$ \\
\hline Egeria densa & 0,5 & $2.000,0$ & 488,6 & .. & 977,2 & \\
\hline Salvinia auriculata & 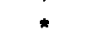 & & & & & \\
\hline \multicolumn{7}{|l|}{ Primavera 21.11.84 } \\
\hline Eichhornia crassipes & 0,5 & $9.600,0$ & 352,0 & 26 & 704,0 & $70 \%$ \\
\hline Egeria densa & 0,5 & $4.700,0$ & 133,6 & .. & 267,2 & \\
\hline Salvinia auriculata & $\star$ & & & & & \\
\hline \multicolumn{7}{|l|}{ Verão 11.03 .85} \\
\hline Eichhornia crassipes & 0,5 & $4.747,8$ & $1.009,0$ & 30 & $2.018,0$ & $60 \%$ \\
\hline Egeria densa & $*$ & & & & & \\
\hline Salvinia auriculata & 0,5 & 252,2 & 53,6 & .. & 107,2 & \\
\hline
\end{tabular}

- Não foram encontradas.

leta de outono. No inverno ocorreram valores mais altos, para o ponto, de sulfato, cloro, potássio, sódio e de silício. Na primavera os teores de cálcio, magnésio e zinco atingiram valores elevados e no verão, fósforo, ferro, manganês e alumínio atingiram seus teores mais altos para o ponto, segundo Beyruth ${ }^{3}, 1989$.

Howard-Williams \& Junk ${ }^{16}$ (1977) afirmam que a concentração de substâncias inorgânicas em tecidos de plantas afeta a cadeia trófica como um todo e citam Bonetto e col. (1969) afirmando que a estrutura trófica de corpos d'água das grandes planícies da América do Sul depende basicamente de macrófitas. Porém, para os nutrientes terem significância ecológica devem ser reciclados ou transferidos para outros componentes do ecossistema. No caso das macrófitas, seu principal papel biogeoquímico consiste no processo de remineralização biológica via cadeia alimentar ou via detrito e o retorno às formas utilizáveis no ecossistema, pela cadeia alimentar de detritos. Esses autores afirmam também que os nutrientes minerais, rapidamente utilizáveis, geralmente estão na fração solúvel, isto é, não na parede celular das macrófitas.

Thomaz \& Esteves ${ }^{32}$ (1984) encontraram o valor de $61,9 \mathrm{em}$ percentagem de peso seco, para a fração de parede celular de E.crassipes de lagoas do litoral fluminense, enquanto que Howard-Williams \& Junk ${ }^{16}$ (1977) encontravam valores médios de $64,9 \pm 1,613 \%$ na Amazônia Central. Os valores de fração de parede celular foram negativamente correlacionados por esses autores a vários elementos nas plantas. Destaca-se o fato das espécies de macrófitas mais facilmente digeríveis (e portanto mais imediatamente utilizáveis) apresentarem baixa fração de parede celular e serem as mais ricas em nutrientes minerais. $O$ aguapé teria um processo de decomposição mais lento - já que a proporção de parede celular é alta - e, ao decair, grande parte desse processo ocorreria no sedimento, como foi apontado para Pontederia cordata por Camargo e col. ${ }^{7}$ (1983). Porém, como $E$. crassipes apresenta, na maior parte de suas estruturas, densidades menores que $1 \mathrm{~g} / \mathrm{cm}^{3}$, parte desse processo pode ocor- 
rer na superfície da água ou próximo a ela, contribuindo para o aumento do teor de nutrientes nesses estratos.

Houve aumento de densidade das comunidades fitoplanctônicas e de invertebrados bentônicos no inverno, provavelmente resultantes da liberação gradativa de matéria orgânica e de nutrientes pela decomposição de $E$. crassipes, notada desde a coleta de outono e mais acentuada no inverno.

Os nutrientes liberados pela decomposição destas macrófitas seriam utilizados por aqueles organismos fitoplanctônicos e bentônicos capacitados a desenvolverem-se bem em baixas temperaturas, no inverno, período em que $E$. crassipes apresentou maior potencial de decomposição, com decaimento de grande parte de sua biomassa.

Esteves \& Camargo $^{10}$ (1986) afirmam que, em regiões tropicais, a ausência de estações bem definidas promove crescimento e morte constante dos indivíduos. Este fato não foi observado durante o período estudado: ficou evidente uma fase de mortalidade mais intensa entre o outono e o inverno e outra de intenso desenvolvimento na primavera e verão, para $E$. crassipes. Isso leva à constatação de que não ocorreu um equilíbrio homogêneo entre perda e ganho de nutrientes, ao longo do ano. Além disso, as $E$. crassipes funcionaram como reservatórios de nutrientes durante parte do ano.

Os exemplares de Egeria densa foram obtidos nas três primeiras coletas, não tendo sido encontrados na coleta de verão. Através da observação local, verificou-se que havia colônia densa dessas plantas na região situada em frente ao ponto $I$, há uns $30 \mathrm{~m}$ da margem, nas coletas de outono e inverno.

Moss $^{22}$ (1980) afirma que exceto em casos onde há alta turbidez inorgânica ou cor na água, a profundidade de colonização para macrófitas submersas é inversamente correlacionada ao "standing-crop" do fitoplâncton $\mathrm{e}$, portanto, ao conteúdo em nutrientes. Os lagos extremamente férteis, com densa população de fitoplâncton são os que têm comunidades de plantas submersas mais restritas, enquanto a vegetação emergente pode ser prolifica nas margens. Neste lago, quando a densidade de organismos fitoplanctônicos foi alta, no inverno, esta planta atingiu maior peso por metro quadrado. As algas predominantes neste período foram flageladas de uma espécie de $\mathrm{Mal}$ lomonas, organismos que por suas dimensōes e pigmentação não interferem efetivamente com a iluminaçäo dos estratos inferiores. Portanto, pode-se concluir que o desenvolvimento mais intenso do fitoplâncton não chegou a prejudicar o crescimento de Egeria. Por outro lado, parece ter ocorrido uma relação inversa entre o produto em pé de Egeria densa e o ciclo de desenvolvimento de Eichhornia crassipes. Egeria apresentou mais altos valores em peso fresco por metro quadrado quando Eichhornia encontrava-se em seu período de decomposição mais intensa (Tabela).

Sob este aspecto, outra relação interessante entre as mactófitas estudadas, foi observada entre espécimes de Salvinia auriculata e Egeria densa. Notou-se que Egeria crescendo em tanques próximos ao lago estudado, em que também havia espécimes de Salvinia, tornavam-se emergentes quando Salvinia cobria toda a superfície dos tanques, sobrevivendo, desta forma, à restrição de luz. Porém, no caso de $E$. crassipes, que se pronuncia muito acima do nível da água, essa emergência de parte do caule de Egeria - entre 5 e $10 \mathrm{~cm}$ não seria suficiente para a exposição à luz, e não se observou essa emergência no lago durante o estudo, porém este comportamento pode ser útil, propiciando a sobrevivência desta planta em corpos d'água com alta densidade de fitoplâncton.

Egeria densa, devido à baixa fração de parede celular, seria comparável a espécies de Elodea, que segundo Thomaz \& Esteves $^{32}$ (1984), podem contribuir com eficácia como fornecedoras de matéria orgânica dissolvida e também de nutrientes inorgânicos facilmente utilizáveis pela biocenose. Barko \& Smart $^{2}$ (1980) comprovaram a capacidade de $E$. densa de obter sua nutrição em fósforo exclusivamente dos sedimentos, observando que na natureza, perda de biomassa por macrófitas submersas ocorre continuamente e provê uma fonte persistente e potencialmente importante de fósforo derivado do sedimento, para outros componentes dos sistemas aquáticos, e que a liberação de fósforo, pelos tecidos em decomposição, pode ser rápida e quantitativamente relevante.

$\mathrm{Na}$ coleta de verão não se avistavam colônias dessas plantas nas margens do lago. Getsinger \& Dillon ${ }^{14}$ (1984) encontraram máximos valores de biomassa no fim do verão e no outono no Lago Marion, na Carolina do Sul, EUA. Relatam, também, que durante o fim do verão ocorreu senescência quando a temperatura da água superficial foi maior que 30 graus centígrados e a massa de ramos des- 
se estrato superior deteriorou.

Cook \& Urmi-Konig ${ }^{8}$ (1984) afirmam que a temperatura ótima para o crescimento é de 16 graus centígrados e a máxima temperatura de crescimento é de 25 graus centígrados. Estes autores citam outro trabalho de Getsinger (1982), na Carolina do Sul, em que havia picos de biomassa na primavera e outono, porém no verão houve declínio no crescimento quando a temperatura excedeu 25 graus centígrados.

No caso do lago de Itapecerica, as temperaturas da água durante a coleta de verão variaram entre 22 e 25 graus centígrados no período da manhã. A temperatura máxima do ar nos sete dias anteriores a essa coleta foi de 31 graus centígrados. Portanto, no período da tarde, a temperatura da água pode ter atingido, freqüentemente, valores maiores que 25 graus centígrados, contribuindo para a ausência dessa planta nos estratos superficiais.

Sculthorpe ${ }^{30}$ (1967) afirma que a temperatura parece ser o principal fator limitante da distribuição alienígena de Egeria densa.

Salvinia auriculata só ocorreram em quantidade suficiente para permitir sua obtenção, no ponto I, na coleta de verão. Não havia camalote dessas plantas nos outros dois pontos em nenhuma das coletas, observando-se, entretanto, grandes quantidades desta planta, secas, acumuladas nas margens, devido à atividade de pescadores que utilizando-se de redes de arrasto de malha fina, acabavam por retirar as plantas durante a passagem da rede. Nas coletas em que sua presença pode ser notada, elas estavam dispersas, à sombra das $E$. crassipes.

Portanto, essas macrófitas não apresentaram densidade suficiente para permitir seu estudo e não parecem, por esse mesmo motivo, ter apresentado contribuição efetiva para o ecossistema como um todo, no periodo estudado, embora em anos anteriores tenha-se observado mais altas densidades, indicando que este ambiente é potencialmente favorável ao seu desenvolvimento.

\section{Influência das Macrófitas no Ambiente}

As macrófitas flutuantes atuam num ecossistema aquático através de dois efeitos básicos: a área de água superficial que elas ocupam e sua contribuição para o ciclo de matéria orgânica e de nutrientes.

Quanto à área ocupada, como visto, Eichhornia crassipes foi a macrófita mais efetivamente atuante, formando camalote durante todo o período de estudo.

Pode-se concluir que esta macrófita afetou negativamente a iluminação de grande área do lago. Essa atuação foi mais efetiva na coleta de primavera (cobrindo aproximadamente $70 \%$ da superfície) a seguir, na coleta de verão $(60 \%)$, tendo interferido menos nas coletas de outono (40\%) e inverno (30\%).

$O$ efeito na penetração da luz faz-se sentir diretamente sobre a fotossíntese e o balanço de oxigênio dissolvido e indiretamente sobre as comunidades animais que são predadas por peixes e por outros animais que se orientam visualmente. A ação como anteparo à luz se contrapõe a de liberação de matéria orgânica e de nutrientes.

Portanto, quanto maior a área coberta, maior o consumo de nutrientes pelas macrófitas e quanto menor a área coberta, maior taxa de liberação de nutrientes e de matéria orgânica, sendo a temperatura do ar o fator determinante da ocorrência e da velocidade desses processos.

As macrófitas, em geral, estiveram confinadas às proximidades do ponto I. Se ocorressem no lago inteiro seria razoável esperar-se correlação: negativa entre área coberta e densidade de fitoplâncton; positiva entre a densidade de fitoplâncton e a liberação de nutrientes e entre a densidade de organismos detritívoros, tais como oligoquetas e alguns quironomídeos, e a liberação de matéria orgânica.

A liberação de matéria orgânica e de nutrientes vai influir diretamente na densidade do fitoplâncton e de animais detritívoros e indiretamente em outros níveis da cadeia trófica.

O impacto de macrófitas aquáticas no ambiente e nas relaçōes bióticas aumenta quando o volume do corpo d'água diminui, o que no caso do lago estudado ocorreu no inverno, na época da seca. Dessa forma é possível explicar as maiores densidades dos organismos fitoplanctônicos e dos macroinvertebrados bentônicos na coleta de inverno, quando as macrófitas ocupavam menor área da superfície da água e liberavam maiores teores de matéria orgânica e de nutrientes.

Quanto ao aspecto sanitário, no lago estudado encontrou-se espécimes de Biomphallaria tenagophila, identificados na Superintendência de Controle de Endemias (SUCEN), onde há registros da ocorrência desta espécie em vários corpos d'água desta região. A presença destes moluscos, vetores da esquistossomose, e o favorecimento de seu desenvolvimento pela ampliação de ambientes adequa- 
dos, devido à presença e abundância de macrófitas, acarreta o aumento do risco de agressões à saúde dos usuários e pesquisadores das águas desta bacia hidrográfica.

Obteve-se correlação positiva significativa entre a densidade de $E$. crassipes e o teor de ferro ( $r s=0,67^{\star *}$ ), entre o peso seco médio dessa macrófitas e o teor de ferro ( $r s=0,54^{*}$ ). $O$ peso seco total das macrófitas por área também apresentou correlação positiva com o teor de ferro da água (rs $\left.=0,58^{\star *}\right)$. O ferro é um macronutriente essencial ao desenvolvimento dos vegetais e segundo Branco ${ }^{6}$ (1986), alguns autores têm dcinonstrado que o enriquecimento das águas em nitrogênio e fósforo faz com que o ferro passe a ser limitante.

Houve correlação positiva entre a área coberta por Eichhornia crassipes e: a temperatura máxima de 7 dias anteriores ( $\left.r s=0,80^{\star *}\right)$, a temperatura do ar na coleta ( $r s=0,69 * *)$, a temperatura da água (rs $\left.=0,78^{* \star *}\right)$, o teor de oxigênio dissolvido ( $r s=0,59 * *)$, a demanda bioquímica de oxigênio ( $r s=0,67 * *$ ) e a condutividade elétrica $\left(r s=0,95^{\star \star \star}\right)$.

Temperaturas mais altas favorecem o desenvolvimento de E.crassipes. Na primavera estas macrófitas estavam em pleno desenvolvimento vegetativo, as condições de luminosidade favoreceram o desenvolvimento do fitoplâncton, não sobreado pelas macrófitas, e não houve grande intensidade pluviométrica. Por outro lado, nessa região há ocorrência de ventos durante a primavera, que podem ter contribuído tanto para o aumento do teor de oxigênio dissolvido na água como para o aumento $\mathrm{da}$ demanda bioquímica desse gás, por aporte de matéria orgânica e de nutrientes mineralizados das margens para a água.

Houve correlações negativas entre a área coberta por Eichhornia e as chuvas de 7 dias $\left(r s=0,80^{\star * \star}\right)$, a cor $(r s=0,59 * *)$ e a turbidez ( $\left.r s=0,80^{* * *}\right)$, os teores de amônio $(r s=0,60 * *)$ e nitrato (rs $\left.=0,74^{\star \star \star}\right)$. As chuvas dos 7 dias anteriores quando mais intensas, interferiram na temperatura da água, reduzindo-a e como foi visto, as baixas temperaturas desfavorecem o desenvolvimento de Eichhornia. Estas macrófitas podem funcionat como um "filtro", reduzindo a açāo do vento sobre a água e também o transporte através da água, de substâncias e partículas responsáveis por conferir cor e turbidez.

Amônio e nitrato podem ser utilizados por estas macrófitas em grandes quantidades.

Com os parâmetros biológicos analisados, houve as seguintes correlações positivas: den- sidade de Eichhornia e a de copepoditos $\left(r s=0,52^{*}\right)$. Esses animais encontrariam maior facilidade de abrigar-se quando a densidade destas plantas estivesse alta. $O$ peso seco médio por planta correlacionou-se positivamente com a eqüitatividade do zooplâncton ( $r s=0,56^{*}$ ), com a densidade de cladóceros $\left(r s=0,53^{*}\right)$ e com o número de táxons de macroinvertebrados bentônicos $\left(t s=0,52^{*}\right)$. O peso seco por planta foi maior no outono em que estas macrófitas ainda liberavam matéria orgânica em quantidade considerável para o ambiente, contribuindo desta forma para a nutrição de organismos capazes de utilizar seus produtos. A área coberta por Eichhornia correlacionou-se positivamente com o número de gêneros de Chlorococcales ( $\left.r s=0,63^{* *}\right)$, com a densidade de Volvocales ( $\left.r s=0,54^{\star}\right)$, com a densidade de Euglenophyceae $\left(r s=0,68^{\star *}\right)$, com a diversidade e eqüitatividade das algas flageladas ( $r s=0,71^{\star *}$ e $r s=0,57^{\star}$ ). Os gêneros Chlorococcales e Volvocales são gêneros abundantes em ambientes com alto nível sapróbico. As densidades dessas algas parecem ter respondido à disponibilidade de nutrientes, o mesmo podendo ser afirmado quanto às $\mathrm{Eu}$ glenophyceae. A diversidade das flageladas foi mais alta na primavera nos pontos II e III, que nas outras coletas nestes mesmos pontos. Quando a área coberta pelas macrófitas foi menor, no inverno, com maior disponibilidade de nutrientes, estas algas atingiram suas mais altas densidades, com diversidade baixa nos 3 pontos do lago.

A área coberta por Eichhornia correlacionou-se positivamente com a densidade do zooplâncton $\left(r s=0,58^{*}\right)$, com a densidade de rotíferos $\left(r s=0,53^{*}\right)$, com a densidade de náuplios (rs $=0,73^{\star *}$ ) e com a diversidade de macroinvertebrados bentônicos $\left(r s=0,52^{*}\right)$. Essas correlações positivas com os parâmetros do zooplâncton e do macrobentos confirmam que estas plantas propiciam abrigo e fontes de nutrição para esses animais, favorecendo-os.

$O$ peso seco por área do total das mactófitas analisadas, correlacionou-se positivamente com a densidade de Tetrasporales ( $\left.r s=0,56^{\star}\right)$, com a equitatividade do zooplâncton $\left(r s=0,54^{\star}\right)$, com a densidade de cladóceros ( $r s=0,52^{*}$ ) e com a densidade de copepoditos ( $r s=0,60^{*}$ ) confirmando as correlações que ocorreram com Eichhornia e reafirmando a validade das explicações aventadas para aquelas correlações.

Houve correlações negativas entre o número de Eichhornia por área e a diversidade e a equitatividade de Chlorophyceae ( $r s=0,61^{* *} \mathrm{e}$ 
$r s=0,65^{\star *}$, respectivamente); entre o peso seco médio de Eichhornia e diversidade e eqüitatividade de Chlorophyceae ( $r s=0,61 * *$ e $\mathrm{rs}=0,69 * *$ respectivamente); entre a área coberta por Eichhornia e o número de gêneros de algas azuis ( $\left.r s=0,55^{* *}\right)$ e a densidade de Dinophyceae ( $r s=0,60^{* *}$ ); entre o peso seco total das macrófitas por área e a diversidade e eqüitatividade das Chlorophyceae ( $r s=0,57^{*} \mathrm{e}$ $\left.\mathrm{rs}=0,64^{\star *}\right)$. Estas algas foram favorecidas nos períodos em que as macrófitas apresentaram menor desenvolvimento, sendo portanto os únicos táxons nitidamente prejudicados pelo aumento da área coberta por Eichhornia.

Esteves $^{9}$ (1982) afirma que Eichhornia crassipes é uma das macrófitas aquáticas mais comuns nos corpos d'água brasileiros, especialmente naqueles em que está ocorrendo eutrofização devido a despejos domésticos e industriais ou devido ao acréscimo de fertilizantes agrícolas. Portanto a sua presença em alta densidade pode ser suficiente para caracterizar ambiente eutrofizado. O aumento de densidade de organismos fitoplanctônicos e do macrobentos, coincidente com o periodo de senescência de Eichhornia crassipes, justifica afirmar o papel de reservatório de nutrientes que esta macrófita desempenha, mantendo a água num aparente estado oligotrófico, aumentando sua produtividade quando ocorre entrada de nutrientes para o sistema. Este processo foi confirmado através de pesquisas em anos subseqüentes*, verificando-se o aumento explosivo desta população, com a manutenção da qualidade da água do lago.

Durante os trabalhos de campo efetuados observou-se que na época das chuvas o excesso de água do lago adentrava o rio Embu-mirim, arrastando quantidades consideráveis de macrófitas, através de um canal de um $m$ de largura existente entre o rio e o lago. Entre o lago e o rio, conserva-se um estreito de terra de aproximadamente $5 \mathrm{~m}$ de largura, coberto por densa vegetação arbustiva, capaz de conter a entrada de volumes muito grandes de macrófitas para o rio. Porém, a população humana ribeirinha tem contribuido direta e indiretamente para a remoção desta cobertura vegetal terrestre e para a eutrofização desta bacia. Com a ausência de proteção nas áreas entre as lagoas marginais e o rio, pode-se prever a entrada maciça de grandes quantidades de macrófitas para o rio.

A alta densidade de gramíneas nas margens do rio, de bancos de gramíneas formando ilhotes

* Dados inéditos. em seu leito e sua alta sinuosidade na região próxima à foz pode ter evitado, até o momento, o ingresso de grandes quantidades de macrófitas livre flutuantes no reservatório de Guarapiranga. Porém, a urbanização e o desmatamento das áreas ribeirinhas pode diminuir o efeito destas barreiras naturais, especialmente para plantas menores como Salvinia. Ultrapassadas estas barreiras naturais, as macrófitas podem atingir o rio e da mesma forma atingir o reservatório de Guarapiranga. A situação de eutrofização atual desta represa pode contribuir para o desenvolvimento maciço e problemático de macrófitas livre flutuantes prejudicando a utilização do reservatório, bem como seu manejo, com conseqüências danosas à saúde dos usuários, comprometendo usos nobres como navegação, balneabilidade e abastecimento.

\section{Conclusões}

Através da análise dos dados obtidos pode-se afirmar que:

a) As macrófitas flutuantes, principalmente $E$. crassipes exerceram papel fundamental na dinâmica trófica do lago, principalmente por sua atuação nos ciclos de nutrientes, no de detritos e na iluminação da água.

b) Essa ação refletiu-se na quantidade e qualidade de organismos fitoplanctônicos, zooplanctônicos, e na dos macroinvertebrados bentônicos.

c) As macrófitas estudadas foram acentuadamente afetadas pela temperatura e luminosidade, refletindo em seu desenvolvimento, mais claramente os fatores alóctones, que os autóctones do lago estudado.

Ficou evidente a necessidade de proteção vegetal arbustiva nas margens do lago, paralelas ao rio, evitando a entrada de massas de macrófitas para o mesmo nos períodos de enchente. Essa entrada poderia ser danosa ao contribuir para o ingresso dessas massas vegetais no reservatório de Guarapiranga.

\section{Agradecimentos}

Ao Prof.Dr. Oswaldo Paulo Forattini pelas sugestões apresentadas.

BEYRUTH, Z. [Aquatic macrophytes from a marginal pond at Embu-mirim river, S.Paulo, Brazil]. Rev. Saúde públ., S.Paulo, 26: 272-82, 1992 . In the years $1984 / 1985$, limnological surveys were carried out at a marginal pond of the 
Embu-mirim river belonging to the hydrographic basin of Guarapiranga Reservoir (S. Paulo, Brazil), in order to obtain data for the determination of physical, chemical and biological parameters. Results obtained from the study of the aquatic macrophytes and their relationships with other environmental parameters are analised. Eichhornia crassipes (Mart.) Solms, the dominant macrophyte, was observed in several water bodies of that basin, including the river it self, thus favoring an evaluation of its behavior in similar water bodies of the basin.

Keywords: Herbs. Fresh water, analysis. Eutrophication. Dams.

\section{Referências Bibliográficas}

\section{AMERICAN PUBLIC HEALTH ASSOCIATION.} Standard methods for examination of water and wastewater. $14^{\text {th }} \mathrm{ed}$. New York, 1975.

2. BARKO, J.W. \& SMART, R.M. Mobilization of sediment $P$ by submerged freshwater macrophytes. Freshwat. Biol., 10: 229-38, 1980.

3. BEYRUTH, Z. Avaliação ecológico-sanitária de um lago em Itapecerica da Serra, SP e ensaio para verificação da possibilidade de utilização da macrófita aquática Eichhornia crassipes como indicadora de poluição. São Paulo, 1989.

[Dissertação de Mestrado - Instituto de Biociências da USP].

4. BEYRUTH, Z. Avaliação ecológico-sanitária de um lago em Itapecerica da Serra, SP. I - Caracterização da área e aspectos climatológicos. [Apresentado ao VI Seminário Regional de Ecologia, São Carlos, 1990].

5. BEYRUTH, Z. Avaliação ecológico-sanitária de um lago em Itapecerica da Serra, SP. II - Qualidade da água. [Apresentado ao VI Seminário Regional de Ecologia São Carlos, 1990]

6. BRANCO, S.M. Hidrobiologia aplicada à engenharia sanitária. São Paulo, CETESB/ASCETESB, 1986.

7. CAMARGO, A.F.M.; ISHII, I.H.; ESTEVES, F.A. Liberação de compostos orgânicos e inorgânicos para a coluna d'água durante o processo de decomposição de duas espécies de macrófitas aquáticas tropicais. An.Sem.Reg.Ecol., São Carlos, 3: 87-99, 1983.

8. COOK, C.D.F. \& URMI-KONIG, K. A revision of genus Egeria. Aquat.Bot., 19: 73-93, 1984.

9. ESTEVES, F.A. Biomass and analysis of the major inorganic components of floating aquatic macrophyte (Eichhornia crassipes (Mart.) Solms) in six reservoirs of S.Paulo State (Brazil). Cienc. $e$ Cult., 34: 1196-200, 1982.

10. ESTEVES, F.A. \& CAMARGO, A.F.M. Sobre o papel das macrófitas aquáticas na estocagem e ciclagem de nutrientes. Acta Limnol. bras., 1: 273-98, 1986.

11. FORATTINI, O.P. Entomologia médica. São Paulo, Faculdade de Saúde Pública da USP, Departamento de Epidemiologia, 1962. v. 1.

12. FORATTINI, O.P. Entomologia médica. São Paulo, Ed.USP, 1965. v. 3.

13. FORNO, I.W. Native distribution of the Salvinia auriculata complex and keys to species identification. Aquat. Bot., 17: 71-82, 1983.
14. GETSINGER, K.D. \& DILLON, C.R. Quiescence, growth and scenescence of Egeria densa in lake Marion. Aquat. Bot., 20: 329-38, 1984.

15. HORSFALL, W.R. Mosquitoes: their bionomics and relation to disease. New York, Hafner Publ., 1972.

16. HOWARD-WILLIAMS, C. \& JUNK, W. The chemical composition of central amazonian macrophytes with special reference to their role in the ecosystem. Arch. Hydrobiol., 79: 445-64, 1977.

17. LAIRD, M. The natural history of larval mosquito habitats. New York, Academic Press, 1988.

18. MARGALEF, R. Ecologia. Barcelona, Ed. Omega, 1974.

19. MITCHELL, D.S. Factors influencing the explosive growth of floating aquatic weeds in tropical areas. Rhodesia Sci. News, 5(1): 17-9, 1971.

20. MITCHELL, D.S., ed. Aquatic vegetation and its use and control: international hydrological decada. Paris, UNESCO, 1974.

21. MITCHELL, D.S. The growth and management of Eichhornia crassipes and Salvinia Spp in their native environment and in allien situations. In: Vartveg, R. \& Pzaska, J., eds. Aquatic weeds in South East Asia. The Hague, Elsevier, 1976. p. 167-76.

22. MOSS, B. Ecology of freshwaters. Oxford, Blackwell Sci. Publ., 1980.

23. NATAL, D.; PAGANELLI, C.H.; SANTOS, J.L.F. Composição da população adulta de Culex (Culex) quinquefasciatus SAY, 1823 em ecótopos próximos à represa Edgard de Souza, Município de Santana do Paranaiba, Estado de São Paulo, Brasil. Rev. bras. Ent., 35: 539-43, 1991.

24. NIE, N.H.; HULL, H.C.; JENKINS, J.G.; STEINBRENNER, K.; BENT, D.H. Statistical package for the social science. $2^{\text {nd }}$ New York, ed. MacGraw Hill, 1975.

25. PALOMBO, C.R Avaliação da propagação vegetativa de Eichhornia crassipes (Mart.) Solms (aguapé) e Pistia stratiopes (alface d’água) da represa Billings, SP. São Paulo, 1989. [Dissertação de Mestrado Instituto de Biociências da USP]

26. PANDIT, A.K. Role of macrophytes in aquatic ecosystems and management of water resources. $J$. environ. Manag., 18: 73-88, 1984.

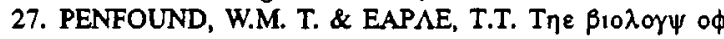
water hyacinth. Ecol. Monogr., 18: 349-472, 1948.

28. POI DE NEIFF, A. \& NEIFF, J.J. Los camalotes de Eichhornia crassipes en aguas loticas del Paraná y su fauna associada. Ecosur, 7(14): 185-99, 1980.

29. ROCHA, A.A. Ensaios com vegetação aquática: aspectos sanitários e ecológicos. Rev. DAE, 103(35): 21-5, 1975.

30. SCULTHORPE, C.D. The biology of aquatic vascular plants. London, Edward Amold Publ., 1967.

31. SIEGEL, S. Estatistica não paramétrica. São Paulo, MacGraw Hill do Brasil, 1975.

32. THOMAZ, S.M. \& ESTEVES, F.A. Estudo da biomassa de algumas espécies de macrófitas aquáticas tropicais quanto ao seu valor nutritivo. An.Sem.Reg.Ecol., 4: 439-67, 1984.

33. WELCH, P.S. Ecological effects of wastes water. Cambridge, Cambridge University Press, 1980.

34. WETZEL, R.G. Limnology. Philadelphia, Saunders, 1975.

Recebido para publicação em 20/1/1992 Aprovado para publicaçāo em 6/3/1992 